Research Paper

\title{
Prognostic significance of BRCA mutations in ovarian cancer: an updated systematic review with meta-analysis
}

\author{
Kai Xu' ${ }^{1, *}$, Shouhua Yang ${ }^{2, *}$, Yingchao Zhao ${ }^{3}$ \\ ${ }^{1}$ Department of Otolaryngology-Head and Neck Surgery, Tongji Hospital, Tongji Medical College, Huazhong University of \\ Science and Technology, Wuhan, Hubei Province, China \\ ${ }^{2}$ Department of Obstetrics and Gynecology, Union Hospital, Tongji Medical College, Huazhong University of Science and \\ Technology, Wuhan, Hubei Province, China \\ ${ }^{3}$ Cancer Center, Union Hospital, Tongji Medical College, Huazhong University of Science and Technology, Wuhan, Hubei \\ Province, China \\ *These authors contributed equally to this work \\ Correspondence to: Yingchao Zhao, email: yingchaozhao321@126.com
}

Keywords: ovarian cancer, BRCA mutation, prognosis, systematic review, meta-analysis

Received: June 29, 2016

Accepted: September 22, 2016

Published: September 28, 2016

\section{ABSTRACT}

There is no consensus on the syntheses concerning the impact of BRCA mutation on ovarian cancer survival. A systematic review and meta-analysis of observational studies was conducted that evaluated the impact of BRCA mutations on the survival outcomes of patients with ovarian cancer. The primary outcome measure was overall survival (OS) and secondary outcome was progression-free survival (PFS). We presented data with hazard ratios (HRs) and $95 \%$ confidence interval (CI) and pooled them using the random-effects models. From 2,624 unique records, 34 eligible studies including 18,396 patients were identified. BRCA1/2 mutations demonstrated both OS and PFS benefits in patients with ovarian cancer (OS: HR $=0.67,95 \% \mathrm{CI}, 0.57$ to 0.78 , $I^{2}=76.5 \%, P<0.001$; PFS: HR $=0.62,95 \% C I, 0.53$ to $\left.0.73, I^{2}=18.1 \%, P=0.261\right)$. For BRCA1 mutation carriers, the HRs for OS and PFS benefits were 0.73 (95\% CI, 0.63 to 0.86 ) and 0.68 ( $95 \%$ CI, 0.52 to 0.89$)$, respectively. For BRCA2 mutation carriers, the HRs for OS and PFS benefits were 0.57 (95\% CI, 0.45 to 0.73 ) and 0.48 ( $95 \%$ CI, 0.30 to 0.75 ), respectively. The results of subgroup analyses for OS stratified by study quality, tumor stage, study design, sample size, number of research center, duration of follow-up, baseline characteristics adjusted and tumor histology were mostly constant across $B R C A 1 / 2, B R C A 1$ and $B R C A 2$ mutation subtypes. In summary, for patients with ovarian cancer, $B R C A$ mutations were associated with improved OS and PFS. Further large-scale prospective cohort studies should be conducted to test its benefits in specific patients.

\section{INTRODUCTION}

As two tumor suppressor genes, BRCA1 and BRCA2 mutation are reported to have been associated with increased risk of developing ovarian cancer and breast cancer [1-3]. Both of them are involved in DNA damage repair through homologous recombination, contributing to genomic instability and malignant transformation [4-6]. Meanwhile, they also involved in cell growth inhibition, gene transcription regulation, apoptosis and other related cellular regulation processes. Previous study reported that patients with $B R C A$-deficient ovarian cancer had improved survival rates as these patients were reported sensitive to platinum-based chemotherapy [7, 8].

Currently, numerous studies have reported the association between $B R C A$ mutations and ovarian cancer mortality, and the results are conflicting. Some investigators have found that ovarian cancer patients with $B R C A$ mutations have more favorable outcomes [9-18], whereas others have indicated null results [7, 19-23].

Two previous published meta-analyses have reported the prognostic impact of $B R C A$ mutations on ovarian cancer mortality $[24,25]$. Sun et al. found that patients with ovarian cancer with $B R C A$ dysfunction 
status tended to have a better outcome [24]. However, this study investigated the effects of $B R C A$ dysfunction status including mutations, protein expression and its promoter methylation, which did not perform the detailed analyses of $B R C A$ mutations. In the meta-analysis by Zhong et al. they only examined the BRCA1 and BRCA2 mutation separately with limited statistical power without examining BRCA1/2 mutation [25]. Therefore, the purpose of this study was to update the meta-analysis on the impact of $B R C A$ mutation carriers versus noncarriers on mortality in patients with ovarian cancer.

\section{RESULTS}

\section{Literature search and study characteristics}

From the initial literature search, we yielded 3595 citations. After exclusion of duplicate publications, 2624 citations remained for further review. 45 potentially eligible reports were selected when irrelevant studies were removed. After reading each full manuscript, we finally identified the 34 studies for meta-analysis. As is shown in Figure 1, we follow the Preferred Reporting Items for Systematic Reviews and Meta-Analyses (PRISMA) flow diagram to conduct this meta-analysis.

\section{Characteristics of included studies}

Table 1 summarizes the baseline characteristics of the included studies. A total of 18,396 patients were included with 32 studies reporting the primary outcome of OS and 13 studies reporting the secondary outcome of PFS. BRCA1, BRCA2 mutation and BRCA1/2 mutation were reported in 15, 14 and 34 studies, respectively. All studies were published between 1996 and 2016. The mean study sample size was 541 (range 40 to 6556) with a percentage of serous cancer ranging from $24.2 \%$ to $100 \%$. $32 \%(11 / 34)$ of the included study were conducted in Europe, 50\% (17/34) in USA or Canada and 9\% (3/34) in Asia, from which 13 were multicenter studies.

As shown in Supplementary Table S1, the quality of the 34 included studies was generally high with 17 studies being more than 7 points.

\section{Survival analysis for $B R C A 1 / 2$-mutation carriers with ovarian cancer}

\section{OS analysis}

32 studies of 17,497 patients with either $B R C A 1$ or $B R C A 2$-mutation (BRCA1/2-mutation) were identified in this analysis. Patients with $B R C A 1 / 2$-mutation had significant $\mathrm{OS}$ benefit $(\mathrm{HR}=0.67,95 \% \mathrm{CI}, 0.57$ to 0.78 , $\mathrm{I}^{2}=76.5 \%, P<0.001$; Figure $\left.2 \mathrm{~A}\right)$.

Subgroup analyses revealed that studies with adequate adjusted variables, but not with inadequate adjusted variables had statistically significant OS benefit in ovarian cancer patients with BRCA1/2-mutation (adequate adjusted variables, $\mathrm{HR}=0.63,95 \% \mathrm{CI}, 0.53$ to 0.75 , $\mathrm{I}^{2}=80.7 \%, P<0.001 ;$ inadequate adjusted variables, $\mathrm{HR}=0.89,95 \% \mathrm{CI}, 0.72$ to $\left.1.10, \mathrm{I}^{2}=0, P=0.992\right)$. OS benefits were also indicated in other subgroups and the HRs for all of the different subgroups are summarized in Table 2A.

\section{PFS analysis}

We identified 13 studies involving 3,485 patients with $B R C A 1 / 2$-mutation for analysis of PFS [7, 10, 13, 20, 26-34]. Patients with $B R C A 1 / 2$-mutation had significant PFS benefit $\left(\mathrm{HR}=0.62,95 \% \mathrm{CI}, 0.53\right.$ to $0.73, \mathrm{I}^{2}=18.1 \%$, $P=0.261$; Figure 2A). The results of subgroup analyses for the association between $B R C A 1 / 2$-mutation and PFS are demonstrated in Table $3 \mathrm{~A}$. In summary, BRCA1/2mutation was significantly associated with improved PFS for studies stratified according to study quality, study design, number of research center, tumor histology and study region. The trend toward an improved PFS was also observed when studies were stratified by tumor stage, sample size, duration of follow-up and optimal debulking ratio.

No evident publication bias was observed by funnel plot asymmetry (Figure 3A) or through Begg's test (OS, $P=0.72$; PFS, $P=0.58$ ) or Egger's test (OS, $P=0.23$; PFS, $P=0.93)$. The trim and fill method applied to further conduct the sensitivity analysis indicated 8 and 5 missing studies in the funnel plot for OS and PFS, respectively (Figure 3). However, imputing these hypothesized studies did not substantially alter the primary pooled estimates (OS, adjusted $\mathrm{HR}=0.49,95 \%$ CI 0.41 to 0.59 ; PFS, adjusted $\mathrm{HR}=0.48,95 \%$ CI 0.40 to 0.58$)$.

\section{Survival analysis for $B R C A 1$-mutation carriers with ovarian cancer}

\section{OS analysis}

15 studies involving 12,995 patients with $B R C A 1$ mutation were identified for meta-analysis $[12,13,27,28$, 32, 34-43]. Patients with BRCA1-mutation had significant OS benefit $\left(\mathrm{HR}=0.73,95 \% \mathrm{CI}, 0.63\right.$ to $0.86, \mathrm{I}^{2}=34.8 \%$, $P<0.001$; Figure 2B).

The results of subgroup analyses for the association between BRCA1-mutation and PFS are presented in Table 2B. We found that ovarian cancer patients with $B R C A 1$-mutation had significantly longer OS than noncarriers, regardless of study quality, sample size, research center or duration of follow-up. Such trend was also noted in studies with cohort study design, adequate baseline characteristics adjusted, all histologic types or conducted in USA or Canada. 
Table 1: Basic characteristics and results of the eligible studies

\begin{tabular}{|c|c|c|c|c|c|c|c|c|c|c|c|c|c|c|c|}
\hline $\begin{array}{c}\text { Authors } \\
\text { and } \\
\text { published } \\
\text { years } \\
\end{array}$ & $\begin{array}{l}\text { Study } \\
\text { design }\end{array}$ & $\begin{array}{l}\text { No. in } \\
\text { study } \\
\text { (cases/ } \\
\text { controls) }\end{array}$ & $\begin{array}{c}\text { Inclusion } \\
\text { period }\end{array}$ & $\begin{array}{l}\text { Country } \\
\text { of origin }\end{array}$ & Stage & Histology & $\begin{array}{c}\text { serous } \\
\text { cancer } \\
(\%)\end{array}$ & $\begin{array}{c}\text { Mutation } \\
\text { detection } \\
\text { method }\end{array}$ & BRCA status & $\begin{array}{l}\text { Germ } \\
\text { /Soma }\end{array}$ & $\begin{array}{c}\text { Single or } \\
\text { multicenter }\end{array}$ & $\begin{array}{c}\text { Follow-up } \\
\text { Duration }\end{array}$ & $\begin{array}{l}\text { Adjusted } \\
\text { variables }\end{array}$ & $\begin{array}{c}\text { Mutation } \\
\text { ratio }\end{array}$ & $\begin{array}{c}\text { Optimal } \\
\text { debulking(\%) }\end{array}$ \\
\hline $\begin{array}{l}\text { Synowiec } \\
\text { (2016) }\end{array}$ & $\mathrm{RC}$ & $17 / 108$ & $2002-2008$ & Poland & I-IV & all & 54.4 & PCR, seq & BRCA1 & Germ & single & NR & $\begin{array}{l}\text { Age, stage, } \\
\text { grade, } \\
\text { histology, } \\
\text { chemotherapy } \\
\text { regimen, } \\
\text { surgery, } \\
\text { grade }\end{array}$ & 13.60 & 61.6 \\
\hline $\begin{array}{l}\text { Sabatier } \\
\text { (2016) }\end{array}$ & $\mathrm{RC}$ & $33 / 71$ & $1994-2011$ & France & I-IV & all & 52.9 & $\begin{array}{c}\text { MLPA, } \\
\text { DHPLC, } \\
\text { Seq }\end{array}$ & $\mathrm{BRCA1} / 2$ & Germ & single & $\begin{array}{c}\text { Mean } 69.8 \\
\text { months with } \\
\text { an s.d. of } 58.4 \\
\text { months. }\end{array}$ & $\begin{array}{c}\text { Age, stage, } \\
\text { grade, } \\
\text { histology, } \\
\text { chemotherapy, } \\
\text { surgery } \\
\end{array}$ & 31.70 & 67.3 \\
\hline $\begin{array}{l}\text { Kotsopoulos } \\
\text { (2016) }\end{array}$ & $\mathrm{RC}$ & $177 / 1244$ & $\begin{array}{l}\text { 1995-1999, } \\
2002-2004\end{array}$ & Canada & I-IV & all & 55.1 & NR & BRCA1/2 & NR & single & \begin{tabular}{|c} 
BRCA1 \\
Mutation: \\
8.1 years \\
(range0.94-20.2) \\
BRCA2 \\
Mutation: 7.6 \\
years \\
(range $2.08-19.9$ ) \\
WT: 9.7 years \\
(range $0.59-20.3$ ) \\
\end{tabular} & $\begin{array}{l}\text { Age, stage, } \\
\text { grade, } \\
\text { histology, } \\
\text { surgery }\end{array}$ & 12.50 & NR \\
\hline $\begin{array}{l}\text { Harter } \\
(2015)\end{array}$ & $\mathrm{RC}$ & $97 / 567$ & NR & Germany & II-IV & all & 73.6 & PCR, seq & $\mathrm{BRCA1} / 2$ & Germ & single & NR & $\begin{array}{l}\text { Age, stage, } \\
\text { grade, } \\
\text { histology }\end{array}$ & 15 & NR \\
\hline $\begin{array}{l}\text { Chen } \\
\text { (2015) }\end{array}$ & $\mathrm{RC}$ & $61 / 195$ & NR & Finland & NR & NR & NR & PCR, Seq & $\mathrm{BRCA} 1 / 2$ & NR & multicenter & NR & \begin{tabular}{|c|} 
Age, grade, \\
stage, residual \\
disease, \\
neoadjuvant \\
therapy, \\
primary therapy \\
outcome \\
\end{tabular} & 23.82 & NR \\
\hline $\begin{array}{l}\text { Candido- } \\
\text { dos-Reis } \\
\text { (2015) }\end{array}$ & $\mathrm{RC}$ & $1496 / 5060$ & NR & U.S.A & I-IV & all & NR & PCR, Seq & BRCA1/2 & Germ & multicenter & NR & \begin{tabular}{|c|} 
Stage, regional, \\
and distant, \\
histology, \\
grade,
\end{tabular} & 22.80 & NR \\
\hline $\begin{array}{l}\text { Cunningham } \\
\text { (2014) }\end{array}$ & $\mathrm{RC}$ & 70/993 & 1992-2011 & U.S.A & I-IV & all & 73 & PCR, seq & $\mathrm{BRCAl} / 2$ & Germ+Soma & single & \begin{tabular}{|l} 
Median 4.5 years \\
(range $0.01-10$ )
\end{tabular} & $\begin{array}{c}\text { Age, stage, } \\
\text { grade, } \\
\text { debulking } \\
\text { status, ascites } \\
\text { present at } \\
\text { surgery, } \\
\text { menopausal } \\
\text { status } \\
\end{array}$ & 6.6 & 85 \\
\hline $\begin{array}{l}\text { Zhang } \\
\text { (2014) }\end{array}$ & $\mathrm{RC}$ & $75 / 250$ & 2012 & NR & II-IV & NR & NR & PCR, seq & $\mathrm{BRCA} 1 / 2$ & NR & single & NR & $\begin{array}{c}\text { Age, grade, } \\
\text { stage, residual } \\
\text { tumor size, } \\
\text { response to } \\
\text { chemotherapy } \\
\text { therapy }\end{array}$ & 23.10 & 67.1 \\
\hline $\begin{array}{l}\text { Rudaitis } \\
\text { (2014) }\end{array}$ & $\mathrm{RC}$ & $55 / 52$ & 2008-2011 & Lithuania & IIII-IV & nonmucinous & 92.5 & PCR, seq & BRCA $1 / 2$ & Germ & single & $\begin{array}{l}\text { BRCA1/2 } \\
\text { Mutation: } \\
\text { Median 35 } \\
\text { months } \\
\text { (range 1-169); } \\
\text { BRCA1/2 WT: } \\
\text { Median 25 } \\
\text { months } \\
\text { (range 8-210) }\end{array}$ & \begin{tabular}{|c|} 
Age,follow- \\
up, ECOG, \\
Histology, \\
subtype, \\
residual \\
tumor size, \\
neoadjuvant \\
therapy, Family \\
history \\
\end{tabular} & 51.40 & NR \\
\hline $\begin{array}{l}\text { Pennington } \\
\text { (2014) }\end{array}$ & $\mathrm{RC}$ & $91 / 276$ & $\mathrm{NR}$ & U.S.A & I-IV & all & 70.3 & PCR, seq & $\mathrm{BRCA1} / 2$ & Germ+Soma & multicenter & NR & $\begin{array}{c}\text { Age, site, } \\
\text { grade, stage, } \\
\text { residual tumor } \\
\text { size }\end{array}$ & 24.8 & 66 \\
\hline $\begin{array}{l}\text { Safra } \\
(2013)\end{array}$ & $\mathrm{RC}$ & $90 / 100$ & 1995-2009 & $\begin{array}{l}\text { U.S.A, } \\
\text { Israeli, } \\
\text { Italia }\end{array}$ & I-IV & all & 69.5 & PCR, Seq & $\mathrm{BRCA1} / 2$ & Germ & multicenter & $\begin{array}{c}\text { Median 56 } \\
\text { months (range } \\
9.3-214 \text { ) }\end{array}$ & \begin{tabular}{|c|} 
Age, stage, \\
residual tumor \\
size, Ethnicity, \\
Institution
\end{tabular} & 47.40 & NR \\
\hline
\end{tabular}




\begin{tabular}{|c|c|c|c|c|c|c|c|c|c|c|c|c|c|c|c|}
\hline \begin{tabular}{|l} 
McLaughlin \\
(2013)
\end{tabular} & $\mathrm{RC}$ & $218 / 1408$ & \begin{tabular}{|l|}
$1995-1999$, \\
2002-2004
\end{tabular} & Canada & I-IV & all & 55.8 & $\begin{array}{c}\text { PTT, } \\
\text { DGGE, } \\
\text { DHPLC, } \\
\text { seq }\end{array}$ & BRCA1/2 & Germ & multicenter & \begin{tabular}{|c|} 
Mean 6.9 years \\
(range $0.3-15.7$ )
\end{tabular} & $\begin{array}{c}\text { Age, histology, } \\
\text { grade, stage }\end{array}$ & 13.40 & NR \\
\hline \begin{tabular}{|l} 
Hyman \\
$(2012)$
\end{tabular} & $\mathrm{RC}$ & $47 / 143$ & 1996-2011 & U.S.A & III-IV & serous & 100 & PCR, seq & BRCA1/2 & Germ & single & Median 2.5 years & $\begin{array}{c}\text { Age, stage, } \\
\text { Optimal } \\
\text { debulking, } \\
\text { IP/IV }\end{array}$ & 24.70 & 76.3 \\
\hline \begin{tabular}{|l|} 
Dann \\
(2012)
\end{tabular} & $\mathrm{RC}$ & $15 / 38$ & 1999-2007 & U.S.A & IIIIV & all & 73.6 & PCR, seq & $\mathrm{BRCA} 1 / 2$ & Germ+Soma & single & NR & $\begin{array}{c}\text { Age, grade, } \\
\text { stage, } \\
\text { histology, } \\
\text { residual } \\
\text { disease, } \\
\text { chemotherapy, } \\
\text { Platinum } \\
\text { response } \\
\end{array}$ & 28.30 & 83 \\
\hline \begin{tabular}{|l|} 
Chan \\
$(2012)$
\end{tabular} & $\mathrm{RC}$ & $69 / 246$ & NR & U.S.A & IIIIV & serous & 100 & PCR, seq & BRCA1/2 & Germ+Soma & single & $\begin{array}{c}\text { Median } 35.4 \\
\text { months (range } \\
1-125 \text { ) }\end{array}$ & $\begin{array}{c}\text { Age, grade, } \\
\text { stage, } \\
\text { histology, } \\
\text { residual } \\
\text { disease, } \\
\text { Ethnicity } \\
\end{array}$ & 21.80 & 65.8 \\
\hline $\begin{array}{l}\text { Alsop } \\
\text { (2012) }\end{array}$ & $\mathrm{RC}$ & $141 / 860$ & 2002-2006 & Australian & I-IV & all & 70.8 & PCR, seq & $\mathrm{BRCA1} / 2$ & Germ & single & $\begin{array}{l}\text { Median } 63.4 \\
\text { months }\end{array}$ & $\begin{array}{c}\text { Age, stage, } \\
\text { grade, } \\
\text { debulking, } \\
\text { primary site, } \\
\text { chemotherapy, } \\
\text { Ethnicity }\end{array}$ & 14.10 & 62.4 \\
\hline $\begin{array}{l}\text { Yang } \\
\text { (2011) }\end{array}$ & $\mathrm{RC}$ & $62 / 252$ & \begin{tabular}{|l|}
$2009-2010$ \\
\end{tabular} & U.S.A & II-IV & serous & 100 & PCR, seq & $\overline{B R C A 1 / 2}$ & Germ+Soma & single & NR & $\begin{array}{l}\text { Age, stage, } \\
\text { grade, } \\
\text { debulking, } \\
\text { Ethnicity }\end{array}$ & 19.70 & 65.8 \\
\hline $\begin{array}{l}\text { Lacour } \\
\text { (2011) }\end{array}$ & $\mathrm{RC}$ & $95 / 183$ & \begin{tabular}{|l|}
$1996-2007$ \\
\end{tabular} & U.S.A & III-IV & all & 68 & PCR, seq & $\mathrm{BRCAl} / 2$ & $\overline{N R}$ & multicenter & $\begin{array}{c}\text { BRCA Mutation: } \\
\text { median } 42.6 ; \\
\text { BRCA WT: } \\
\text { median } 37.5\end{array}$ & $\begin{array}{c}\text { Age, stage, } \\
\text { grade, } \\
\text { histology, } \\
\text { debulking, } \\
\text { response to } \\
\text { chemotherapy, } \\
\text { Institution, } \\
\text { Ethnicity } \\
\end{array}$ & 34.20 & 70.1 \\
\hline \begin{tabular}{|l|} 
Gallagher \\
(2011)
\end{tabular} & $\mathrm{RC}$ & $36 / 74$ & 1996-2006 & U.S.A & III-IV & all & 80.9 & PCR, Seq & BRCA1/2 & Germ & single & $\begin{array}{c}\text { Median } 41 \\
\text { months }\end{array}$ & $\begin{array}{c}\text { Age, stage, } \\
\text { histology, } \\
\text { debulking, } \\
\text { platinum } \\
\text { response, } \\
\text { CA125, } \\
\text { secondary } \\
\text { cytoreduction }\end{array}$ & 32.70 & 60.9 \\
\hline $\begin{array}{l}\text { Hennessy } \\
(2010)\end{array}$ & $\mathrm{RC}$ & $44 / 191$ & 1996-2006 & U.S.A & I-IV & all & 79.1 & PCR,Seq & $\mathrm{BRCA} 1 / 2$ & Germ+Soma & multicenter & $\begin{array}{c}\text { Median 1071days } \\
\text { (range 19-6241) }\end{array}$ & $\begin{array}{c}\text { Age, grade, } \\
\text { stage, residual } \\
\text { disease, } \\
\text { surgery, } \\
\text { chemotherapy }\end{array}$ & 18.70 & 58.7 \\
\hline \begin{tabular}{|l} 
Tan \\
$(2008)$
\end{tabular} & NCC & $22 / 44$ & 1993-1995 & $\overline{\text { UK }}$ & III-IV & all & 81.8 & SCCP, seq & BRCA1/2 & Germ & multicenter & NR & $\begin{array}{l}\text { Age, stage, } \\
\text { histology }\end{array}$ & 33.30 & NR \\
\hline $\begin{array}{l}\text { Chetrit } \\
(2008)\end{array}$ & $\mathrm{RC}$ & $225 / 554$ & \begin{tabular}{|l|}
$1994-1999$ \\
\end{tabular} & Israel & I-IV & all & 57.1 & PCR, seq & $\mathrm{BRCA} 1 / 2$ & Germ & single & $\begin{array}{c}\text { Median 6.2 years } \\
\text { (range 4.2-9.4) }\end{array}$ & $\begin{array}{l}\text { Age, stage, } \\
\text { grade, } \\
\text { menopausal } \\
\text { status }\end{array}$ & 28.90 & NR \\
\hline $\begin{array}{l}\begin{array}{l}\text { Pal } \\
(2007)\end{array} \\
\end{array}$ & $\mathrm{RC}$ & $32 / 200$ & \begin{tabular}{|l|}
$2000-2003$ \\
\end{tabular} & U.S.A & I-IV & all & 57.9 & PCR, seq & BRCA1/2 & Germ & single & NR & $\begin{array}{c}\text { Age, grade, } \\
\text { stage, histology }\end{array}$ & 13.80 & $\mathrm{NR}$ \\
\hline $\begin{array}{l}\text { Majdak } \\
\text { (2005) }\end{array}$ & $\mathrm{NCC}$ & $18 / 187$ & \begin{tabular}{|l|}
$1994-2002$ \\
\end{tabular} & Poland & I-IV & all & 64.9 & $\begin{array}{l}\text { F-CSGE, } \\
\text { PCR, Seq }\end{array}$ & $\mathrm{BRCA} 1 / 2$ & Germ & single & NR & $\begin{array}{l}\text { Age, stage, } \\
\text { grade, } \\
\text { histology, } \\
\text { residual, } \\
\text { outcome, } \\
\text { Infertility }\end{array}$ & 8.8 & 52.2 \\
\hline $\begin{array}{l}\text { Cass } \\
(2003)\end{array}$ & $\mathrm{RC}$ & $34 / 37$ & \begin{tabular}{|l|}
$1990-1998$ \\
\end{tabular} & U.S.A & I-IV & all & 84.5 & $\begin{array}{c}\text { PCR, } \\
\text { SSCR, seq }\end{array}$ & BRCA1/2 & Germ & single & $\begin{array}{l}\text { Median } \\
\text { 72months }\end{array}$ & $\begin{array}{c}\text { Age, stage, } \\
\text { grade, } \\
\text { histology, } \\
\text { CA125, } \\
\text { optimal } \\
\text { cytoreduction, } \\
\text { Primary } \\
\text { chemotherapy, }\end{array}$ & 47.90 & NR \\
\hline
\end{tabular}




\begin{tabular}{|c|c|c|c|c|c|c|c|c|c|c|c|c|c|c|c|}
\hline $\begin{array}{l}\text { David } \\
(2002)\end{array}$ & $\mathrm{RC}$ & $234 / 662$ & 1994-1999 & Israel & NR & all & $\mathrm{NR}$ & SCCP,seq & BRCAl/2 & Germ & single & $\begin{array}{c}\text { Median } 30.5 \\
\text { months(range } \\
20-64) \\
\end{array}$ & $\begin{array}{c}\text { age, stage, } \\
\text { family history }\end{array}$ & 26.10 & NR \\
\hline $\begin{array}{l}\text { Buller } \\
(2002) \\
\end{array}$ & $\mathrm{NCC}$ & $24 / 48$ & NR & U.S.A & I-IV & all & 74.6 & $\begin{array}{l}\text { PCR,PTT, } \\
\text { seq, SSCP } \\
\end{array}$ & BRCA1 & Germ+Soma & single & NR & I & 23.60 & NR \\
\hline $\begin{array}{l}\text { Zweemer } \\
(2001)\end{array}$ & $\mathrm{NCC}$ & $23 / 17$ & NR & Netherland & I-IV & all & 55 & PCR,PTT & BRCA1/2 & Germ & single & \begin{tabular}{|c} 
Mean 47 months \\
(range 6-168)
\end{tabular} & $\begin{array}{c}\text { age, stage, } \\
\text { grade }\end{array}$ & 57.50 & NR \\
\hline \begin{tabular}{|l} 
Ramus \\
$(2001)$ \\
\end{tabular} & $\mathrm{RC}$ & $27 / 71$ & |1992-1997 & Israel & I-IV & all & 77.6 & $\begin{array}{c}\text { RCR, SSCP, } \\
\text { seq }\end{array}$ & BRCA1/2 & Germ & single & NR & I & 27.60 & NR \\
\hline $\begin{array}{l}\text { Boyd } \\
(2000)\end{array}$ & $\mathrm{RC}$ & $88 / 101$ & |1986-1998 & U.S.A & I-IV & all & 64 & PCR, Seq & BRCA1/2 & Germ & multicenter & $\begin{array}{c}\text { BRCA Mutation: } \\
\text { median } 57 \\
\text { months; BRCA } \\
\begin{array}{c}\text { WT: median } 59 \\
\text { months }\end{array} \\
\end{array}$ & $\begin{array}{c}\text { Histology, } \\
\text { grade, stage, } \\
\text { cytoreductive } \\
\text { surgery, } \\
\text { chemotherapy } \\
\end{array}$ & 46.60 & 50.8 \\
\hline $\begin{array}{l}\text { Pharoah } \\
(1999)\end{array}$ & $\mathrm{NCC}$ & $38 / 127$ & NR & UK & I-IV & all & 24.2 & $\begin{array}{c}\text { PTT, SSCP, } \\
\text { Seq }\end{array}$ & BRCA1/2 & Germ & multicenter & NR & I & 56 & NR \\
\hline \begin{tabular}{|l}
$\begin{array}{l}\text { Johannsson } \\
(1998)\end{array}$ \\
\end{tabular} & $\mathrm{NCC}$ & $38 / 97$ & 1985-1995 & Sweden & I-IV & all & NR & \begin{tabular}{|c} 
PTT, SSCP, \\
Seq \\
\end{tabular} & BRCA1 & Germ & multicenter & NR & / & 28.15 & NR \\
\hline $\begin{array}{l}\text { Aida } \\
\text { (1998) }\end{array}$ & $\mathrm{NCC}$ & $13 / 49$ & 1983-1997 & Japan & III & all & 83.9 & $\begin{array}{c}\text { SSCP, PCR, } \\
\text { Seq }\end{array}$ & BRCA1 & Germ & multicenter & $\begin{array}{c}\text { Mean } 54.8 \\
\text { months }\end{array}$ & $\begin{array}{c}\text { Age, histology, } \\
\text { stage, } \\
\text { chemotherapy, } \\
\text { response, } \\
\end{array}$ & 57.80 & NR \\
\hline $\begin{array}{l}\text { Rubin } \\
(1996)\end{array}$ & $\mathrm{NCC}$ & $43 / 43$ & 1998-1996 & U.S.A & III-IV & all & 81.1 & $\begin{array}{c}\text { SSCP, PCR, } \\
\text { Seq }\end{array}$ & BRCA1 & Germ & multicenter & Mean 71 months & / & 50 & NR \\
\hline
\end{tabular}

\section{PFS analysis}

We identified 3 studies involving 1,640 patients with BRCA1-mutation for analysis of PFS [13, 27, 28]. Patients with $B R C A 1$-mutation had significant PFS benefit $\left(\mathrm{HR}=0.68,95 \% \mathrm{CI}, 0.52\right.$ to $0.89, \mathrm{I}^{2}=0, P<0.001$; Figure $2 \mathrm{~B}$ ). The results of subgroup analyses for the association between BRCA1-mutation and PFS are demonstrated in Table 3B.
No evident publication bias was observed by funnel plot asymmetry (Figure 3B) or through Egger's test $(P=0.84)$ or Begg's test $(P=0.83)$ for OS. The trim and fill method applied to further conduct the sensitivity analysis indicated one missing study in the funnel plot for OS (Figure 3). However, imputing this hypothesized study did not alter the primary pooled estimates (adjusted $\mathrm{HR}=0.66,95 \% \mathrm{CI}$, 0.56 to 0.78 ). We did not investigate the publication bias for PFS due to the limited number of studies.

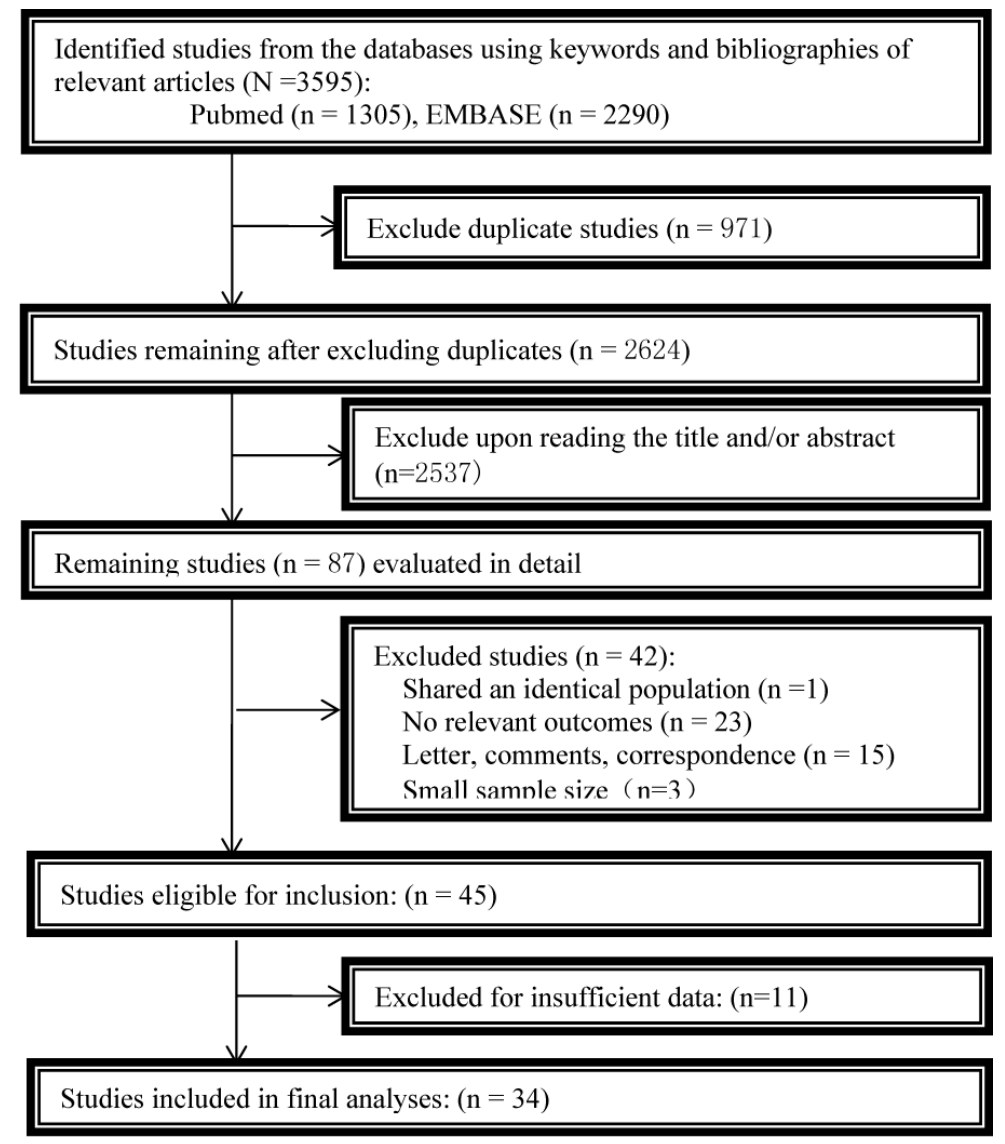

Figure 1: Flowchart of the study selection. 
Table 2A: Subgroup analyses stratified by some of the baseline characteristics for associations between $B R C A 1 / 2$ mutation and overall survival

\begin{tabular}{|c|c|c|c|c|c|}
\hline & HR & $95 \% \mathrm{CI}$ & $\begin{array}{c}\text { Degree of heterogeneity } \\
\left(I^{2} \text { statistics; \%) }\right.\end{array}$ & $P$ & $\begin{array}{l}\text { No. of included } \\
\text { Studies }\end{array}$ \\
\hline \multicolumn{6}{|l|}{ Total } \\
\hline & 0.67 & 0.57 to 0.78 & 76.5 & $<0.001$ & 32 \\
\hline \multicolumn{6}{|l|}{ Study quality } \\
\hline Score $>7$ & 0.67 & 0.56 to 0.80 & 74.4 & $<0.001$ & 15 \\
\hline$\leq 7$ & 0.66 & 0.50 to 0.87 & 79.2 & $<0.001$ & 17 \\
\hline \multicolumn{6}{|l|}{ Stage of disease } \\
\hline I-IV & 0.79 & 0.66 to 0.94 & 76.5 & $<0.001$ & 19 \\
\hline II-IV & 0.47 & 0.37 to 0.59 & 0 & 0.423 & 5 \\
\hline III-IV & 0.64 & 0.49 to 0.83 & 43.2 & $<0.091$ & 8 \\
\hline \multicolumn{6}{|l|}{ Study design } \\
\hline Cohort & 0.67 & 0.56 to 0.79 & 80.1 & $<0.001$ & 24 \\
\hline Case-control & 0.65 & 0.44 to 0.96 & 56.7 & 0.024 & 8 \\
\hline \multicolumn{6}{|l|}{ Sample size } \\
\hline$\geq 200$ & 0.68 & 0.56 to 0.83 & 85.5 & $<0.001$ & 5 \\
\hline$<200$ & 0.67 & 0.54 to 0.83 & 45.7 & 0.021 & 17 \\
\hline \multicolumn{6}{|l|}{ Research center } \\
\hline Single & 0.67 & 0.53 to 0.84 & 76.7 & $<0.001$ & 20 \\
\hline Multicenter & 0.70 & 0.57 to 0.86 & 75.5 & $<0.001$ & 11 \\
\hline \multicolumn{6}{|c|}{ Duration of follow-up } \\
\hline \multicolumn{6}{|l|}{ Months } \\
\hline$>60$ & 0.77 & 0.65 to 0.91 & 77.7 & $<0.001$ & 20 \\
\hline$\leq 60$ & 0.58 & 0.49 to 0.68 & 40.7 & 0.069 & 12 \\
\hline \multicolumn{6}{|c|}{$\begin{array}{l}\text { Adequate baseline } \\
\text { characteristics adjusted }\end{array}$} \\
\hline Yes & 0.63 & 0.53 to 0.75 & 80.7 & $<0.001$ & 26 \\
\hline No & 0.89 & 0.72 to 1.10 & 0 & 0.922 & 6 \\
\hline \multicolumn{6}{|l|}{ Histology } \\
\hline All & 0.68 & 0.58 to 0.79 & 76.2 & $<0.001$ & 31 \\
\hline High-grade serous & 0.62 & 0.43 to 0.90 & 84 & $<0.001$ & 4 \\
\hline \multicolumn{6}{|l|}{ Mutation ratio } \\
\hline$>25 \%$ & 0.70 & 0.60 to 0.81 & 36.3 & 0.068 & 17 \\
\hline$\leq 25 \%$ & 0.65 & 0.51 to 0.82 & 85.5 & $<0.001$ & 15 \\
\hline \multicolumn{6}{|l|}{ Region } \\
\hline Europe & 0.65 & 0.48 to 0.88 & 64.8 & 0.002 & 10 \\
\hline America/Canada & 0.72 & 0.59 to 0.89 & 80.3 & $<0.001$ & 16 \\
\hline Asia & 0.69 & 0.51 to 0.93 & 12.0 & 0.321 & 3 \\
\hline \multicolumn{6}{|c|}{ Optimal debulking ratio } \\
\hline$>65 \%$ & 0.58 & 0.48 to 0.72 & 41.6 & 0.090 & 9 \\
\hline$\leq 65 \%$ & 0.53 & 0.35 to 0.79 & 60.9 & 0.037 & 5 \\
\hline
\end{tabular}

Abbreviations: $\mathrm{HR}=$ hazard ratio; $\mathrm{CI}=$ confidence interval.

\section{Survival analysis for $B \boldsymbol{R} C \boldsymbol{A} 2$-mutation carriers with ovarian cancer}

\section{OS analysis}

14 studies including 12,933 patients with $B R C A 2-$ mutation were involved for meta-analysis $[12,13,27,28$, 32, 35-43]. Patients with BRCA2-mutation had significant OS benefit (HR $=0.57,95 \% \mathrm{CI}, 0.45$ to $0.73, \mathrm{I}^{2}=50.3 \%$, $P<0.001$; Figure 2C).
The results of subgroup analyses for the association between $B R C A 2$-mutation and $\mathrm{OS}$ are presented in Table $2 \mathrm{C}$. We found that ovarian cancer patients with $B R C A 2$-mutation had significantly longer OS than noncarriers, regardless of research center, duration of followup or histologic type. Such trend was also noted in studies with high quality, II-IV disease stage, cohort study design, sample size larger than 200, adequate baseline characteristics adjusted or conducted in USA or Canada. 
Table 2B: Subgroup analyses stratified by some of the baseline characteristics for associations between $B R C A 1$ mutation and overall survival

\begin{tabular}{|c|c|c|c|c|c|}
\hline & HR & $95 \% \mathrm{CI}$ & $\begin{array}{c}\text { Degree of heterogeneity } \\
\left(\mathbf{I}^{2} \text { statistics; \% }\right)\end{array}$ & $\boldsymbol{P}$ & $\begin{array}{c}\begin{array}{c}\text { No. of included } \\
\text { Studies }\end{array} \\
\end{array}$ \\
\hline Total & 0.73 & 0.63 to 0.86 & 34.8 & 0.090 & 15 \\
\hline \multicolumn{6}{|l|}{ Study quality } \\
\hline Score $>7$ & 0.76 & 0.63 to 0.91 & 35.2 & 0.137 & 9 \\
\hline$\leq 7$ & 0.66 & 0.47 to 0.91 & 44.6 & 0.108 & 6 \\
\hline \multicolumn{6}{|l|}{ Stage of disease } \\
\hline I-IV & 0.72 & 0.58 to 0.88 & 47.1 & 0.057 & 9 \\
\hline II-IV & 0.79 & 0.49 to 1.27 & 0 & 0.816 & 2 \\
\hline III-IV & 0.69 & 0.46 to 1.04 & 50.2 & 0.110 & 4 \\
\hline \multicolumn{6}{|l|}{ Study design } \\
\hline Cohort & 0.73 & 0.63 to 0.86 & 22.6 & 0.221 & 12 \\
\hline Case-control & 0.54 & 0.24 to 1.24 & 69.9 & 0.036 & 3 \\
\hline \multicolumn{6}{|l|}{ Sample size } \\
\hline$\geq 200$ & 0.76 & 0.64 to 0.92 & 33.3 & 0.152 & 9 \\
\hline$<200$ & 0.65 & 0.47 to 0.90 & 46.2 & 0.098 & 6 \\
\hline \multicolumn{6}{|l|}{ Research center } \\
\hline Single & 0.77 & 0.65 to 0.90 & 0 & 0.461 & 9 \\
\hline Multicenter & 0.69 & 0.52 to 0.91 & 63.6 & 0.017 & 6 \\
\hline \multicolumn{6}{|l|}{ Duration of follow-up } \\
\hline$>60$ & 0.74 & 0.61 to 0.88 & 51.5 & 0.029 & 10 \\
\hline$\leq 60$ & 0.68 & 0.47 to 0.99 & 0 & 0.645 & 5 \\
\hline \multicolumn{6}{|c|}{$\begin{array}{l}\text { Adequate baseline } \\
\text { characteristics adjusted }\end{array}$} \\
\hline Yes & 0.70 & 0.59 to 0.83 & 35.5 & 0.099 & 13 \\
\hline No & 0.93 & 0.71 to 1.21 & 0 & 0.568 & 2 \\
\hline \multicolumn{6}{|l|}{ Histology } \\
\hline All & 0.70 & 0.59 to 0.83 & 35.5 & 0.099 & 13 \\
\hline High-grade serous & 0.78 & 0.53 to 1.14 & 74.0 & 0.009 & 4 \\
\hline \multicolumn{6}{|l|}{ Region } \\
\hline Europe & 0.82 & 0.64 to 1.06 & 44.3 & 0.166 & 3 \\
\hline America/Canada & 0.77 & 0.62 to 0.96 & 31.2 & 0.190 & 7 \\
\hline Asia & 0.48 & 0.20 to 1.19 & 27.1 & 0.242 & 2 \\
\hline
\end{tabular}

Abbreviations: $\mathrm{HR}=$ hazard ratio; $\mathrm{CI}=$ confidence interval.

\section{PFS analysis}

We identified 3 studies involving 1,640 patients with $B R C A 2$-mutation for analysis of PFS [13, 27, 28]. Patients with $B R C A 2$-mutation had significant $P F S$ benefit $\left(\mathrm{HR}=0.48,95 \% \mathrm{CI}, 0.30\right.$ to $0.75, \mathrm{I}^{2}=0, P<0.001$; Figure $2 \mathrm{C}$ ). The results of subgroup analyses for the association between BRCA2-mutation and PFS are demonstrated in Table 3C.

No evident publication bias was observed by funnel plot asymmetry (Figure 3C) or through Egger's test $(P=0.54)$ or Begg's test $(P=0.96)$ for OS. The trim and fill method applied to further conduct the sensitivity analysis indicated 4 missing studies in the funnel plot for OS (Figure 3). However, imputing these hypothesized studies did not alter the primary pooled estimates (adjusted $\mathrm{HR}=0.38,95 \% \mathrm{CI} 0.29$ to 0.50 ). We did not investigate the publication bias for PFS due to the limited number of studies.

\section{DISCUSSION}

The aim of this meta-analysis was to examine the association between $B R C A$ mutation status and ovarian cancer survival (OS and PFS). By pooling the outcomes of 18,396 ovarian cancer patients from 34 individual studies, we found that $B R C A$ mutation (BRCA1/2, BRCA1 and $B R C A 2$ ) carriers had significantly improved OS and PFS benefits in ovarian cancer patients. Subgroup analysis revealed that this survival benefits remained constant 
Table 2C: Subgroup analyses stratified by some of the baseline characteristics for associations between $B R C A 2$ mutation and overall survival

\begin{tabular}{|c|c|c|c|c|c|}
\hline & HR & $95 \% \mathrm{CI}$ & $\begin{array}{l}\text { Degree of heterogeneity } \\
\left(I^{2} \text { statistics; \%) }\right.\end{array}$ & $P$ & $\begin{array}{l}\text { No. of included } \\
\text { Studies }\end{array}$ \\
\hline Total & 0.57 & 0.45 to 0.73 & 50.3 & 0.016 & 14 \\
\hline $\begin{array}{c}\text { Study quality } \\
\text { Score }>7 \\
\leq 7\end{array}$ & $\begin{array}{l}0.53 \\
0.71\end{array}$ & $\begin{array}{l}0.40 \text { to } 0.70 \\
0.41 \text { to } 1.21\end{array}$ & $\begin{array}{l}50.2 \\
46.7\end{array}$ & $\begin{array}{l}0.034 \\
0.131\end{array}$ & $\begin{array}{c}10 \\
4\end{array}$ \\
\hline $\begin{array}{l}\text { Stage of disease } \\
\text { I-IV } \\
\text { II-IV } \\
\text { III-IV }\end{array}$ & $\begin{array}{l}0.56 \\
0.46 \\
0.64\end{array}$ & $\begin{array}{l}0.43 \text { to } 0.74 \\
0.21 \text { to } 0.97 \\
0.32 \text { to } 1.28\end{array}$ & $\begin{array}{l}39.6 \\
37.2 \\
64.0\end{array}$ & $\begin{array}{l}0.103 \\
0.207 \\
0.062\end{array}$ & $\begin{array}{l}9 \\
2 \\
3\end{array}$ \\
\hline $\begin{array}{l}\text { Study design } \\
\text { Cohort } \\
\text { Case-control }\end{array}$ & $\begin{array}{l}0.56 \\
0.54\end{array}$ & $\begin{array}{l}0.43 \text { to } 0.72 \\
0.13 \text { to } 2.14\end{array}$ & $\begin{array}{l}48.3 \\
70.7\end{array}$ & $\begin{array}{l}0.030 \\
0.065\end{array}$ & $\begin{array}{c}12 \\
2\end{array}$ \\
\hline $\begin{array}{r}\text { Sample size } \\
\geq 200 \\
<200\end{array}$ & $\begin{array}{l}0.54 \\
0.63\end{array}$ & $\begin{array}{l}0.41 \text { to } 0.73 \\
0.38 \text { to } 1.04\end{array}$ & $\begin{array}{l}51.4 \\
52.9\end{array}$ & $\begin{array}{l}0.036 \\
0.075\end{array}$ & $\begin{array}{l}9 \\
5\end{array}$ \\
\hline $\begin{array}{l}\text { Research center } \\
\text { Single } \\
\text { Multicenter }\end{array}$ & $\begin{array}{l}0.52 \\
0.65\end{array}$ & $\begin{array}{l}0.39 \text { to } 0.70 \\
0.43 \text { to } 0.89\end{array}$ & $\begin{array}{l}24.6 \\
71.5\end{array}$ & $\begin{array}{l}0.224 \\
0.007\end{array}$ & $\begin{array}{l}9 \\
5\end{array}$ \\
\hline $\begin{array}{l}\text { Duration of follow-up } \\
\begin{array}{l}\text { Months } \\
\quad>60 \\
\leq 60\end{array}\end{array}$ & $\begin{array}{l}0.59 \\
0.52\end{array}$ & $\begin{array}{l}0.44 \text { to } 0.78 \\
0.28 \text { to } 0.94\end{array}$ & $\begin{array}{l}55.8 \\
45.4\end{array}$ & $\begin{array}{l}0.016 \\
0.139\end{array}$ & $\begin{array}{c}10 \\
4\end{array}$ \\
\hline $\begin{array}{l}\text { Adequate baseline } \\
\text { characteristics adjuste } \\
\text { Yes } \\
\text { No }\end{array}$ & $\begin{array}{l}0.52 \\
0.92\end{array}$ & $\begin{array}{l}0.40 \text { to } 0.68 \\
0.61 \text { to } 1.39\end{array}$ & $\begin{array}{c}48.7 \\
0\end{array}$ & $\begin{array}{l}0.029 \\
0.881\end{array}$ & $\begin{array}{c}12 \\
2\end{array}$ \\
\hline $\begin{array}{l}\text { Histology } \\
\text { All } \\
\text { High-grade serous }\end{array}$ & $\begin{array}{l}0.56 \\
0.54\end{array}$ & $\begin{array}{l}0.44 \text { to } 0.72 \\
0.32 \text { to } 0.93\end{array}$ & $\begin{array}{l}36.7 \\
79.8\end{array}$ & $\begin{array}{l}0.097 \\
0.002\end{array}$ & $\begin{array}{c}12 \\
4\end{array}$ \\
\hline $\begin{array}{l}\text { Region } \\
\text { Europe } \\
\text { America/Canada } \\
\text { Asia }\end{array}$ & $\begin{array}{l}0.61 \\
0.51 \\
0.88\end{array}$ & $\begin{array}{l}0.34 \text { to } 1.07 \\
0.34 \text { to } 0.76 \\
0.44 \text { to } 1.75\end{array}$ & $\begin{array}{c}59.0 \\
66.5 \\
/\end{array}$ & $\begin{array}{l}0.087 \\
0.006 \\
/\end{array}$ & $\begin{array}{l}3 \\
7 \\
1\end{array}$ \\
\hline
\end{tabular}

Abbreviations: $\mathrm{HR}=$ hazard ratio; $\mathrm{CI}=$ confidence interval.

irrespective of study quality, tumor stage, study design, sample size, number of research center, duration of followup, baseline characteristics adjusted and tumor histology.

This meta-analysis showed that patients who were $B R C A$ mutation carriers had a $33 \%, 27 \%$ and $43 \%$ reduction in all-cause mortality for $B R C A 1 / 2, B R C A 1$ and $B R C A 2$ mutants respectively, while patients had a $38 \%$, $32 \%$ and $52 \%$ reduction in progression-free mortality for $B R C A 1 / 2, B R C A 1$ and $B R C A 2$ mutants, respectively. Individually, however, some of the studies had reported contradictory findings [7, 19-22]: some studies have indicated significantly reduced all-cause mortality or progression-free mortality among $B R C A$ mutation carriers [9-14], whereas Kotsopoulos et al. reported that the mortality risk in ovarian cancer patients was significantly poorer for $B R C A$ mutation carriers than for non-carriers $(\mathrm{HR}=1.67 ; 95 \%$ CI 1.34 to 2.08$)$ [19]. The present metaanalysis with the largest number of patients investigated both survival (OS) and progression outcomes (PFS) for ovarian cancer, incorporating not only the general $B R C A$ mutation status but also two subtypes, including $B R C A 1$ and $B R C A 2$ mutation status.

It has been reported that germline $B R C A 1 / 2$ mutations occur in approximately 10 to $20 \%$ of patients with invasive epithelial ovarian cancers [7, 9-14, 19-22], and more than $20 \%$ of patients with high-grade serous ovarian cancer [12]. BRCA1/2 tumor suppressor genes are reported to be involved in DNA repair through homologous recombination, through which pathway genes are unable to repair DNA double-strand, resulting 
A1

Study

Overall survival(BRCA1/2 mutation)

Synowiec (2016)

Sabatier (2016)

Kotsopoulos (2016)

Chen (2015)

Candido-dos-Reis (2014)

Zhang (2014)

Rudaitis (2014)

Pennington (2014)

Cunningham (2014)

Safra (2013)

McLaughlin (2013)

Hyman (2012)

Dann (2012)

Chan (2012)

Alsop (2012)

Yang (2011)

Lacour (2011)

Gallagher (2011)

$\operatorname{Tan}(2008)$

Chetrit (2008)

Pal (2007)

Majdak (2005)

Cass (2003)

David (2002)

Buller (2002)

Zweemer (2001)

Ramus (2001)

Boyd (2000)

Pharoah (1999)

Johannsson (1998)

Aida (1998)

Rubin (1996)

Subtotal (I-squared $=76.5 \%, p=0.000$ )

NOTE: Weights are from random effects analysis
HR $(95 \%$

Weight

$0.14(0.03,0.65) \quad 0.85$

$1.25(0.62,2.50) \quad 2.53$

$1.67(1.34,2.08) \quad 4.90$

$0.42(0.26,0.67) \quad 3.58$

$0.95(0.85,1.06) \quad 5.31$

$0.42(0.27,0.65) \quad 3.74$

$0.84(0.42,1.69) \quad 2.52$

$0.50(0.40,0.80) \quad 4.25$

$0.88(0.62,1.26) \quad 4.20$

$0.45(0.28,0.72) \quad 3.57$

$1.00(0.83,1.22) \quad 5.02$

$0.52(0.29,0.93) \quad 3.02$

$0.71(0.15,3.30) \quad 0.81$

$0.51(0.35,0.75) \quad 4.06$

$0.61(0.42,0.88) \quad 4.12$

$0.55(0.35,0.86) \quad 3.69$

$0.52(0.34,0.80) \quad 3.80$

$0.33(0.12,0.86) \quad 1.65$

$\begin{array}{ll}0.33(0.12,0.86) & 1.65 \\ 0.22(0.09,0.55) & 1.85\end{array}$

$0.72(0.57,0.90) \quad 4.86$

$0.43(0.18,1.01) \quad 1.97$

$0.39(0.18,0.84) \quad 2.26$

$\begin{array}{ll}0.39(0.18,0.84) & 2.26 \\ 0.50(0.14,1.80) & 1.12\end{array}$

$0.72(0.56,0.92) \quad 4.77$

$1.16(0.43,3.09) \quad 1.64$

$0.87(0.38,1.97) \quad 2.09$

$\begin{array}{ll}0.77(0.40,1.49) & 2.69\end{array}$

$\begin{array}{ll}0.77(0.40,1.49) & 2.69 \\ 0.79(0.63,1.00) & 4.85\end{array}$

$0.90(0.69,1.17) \quad 4.69$

$120(0.50,280) \quad 1.97$

$0.28(0.08,0.93) \quad 1.19$

$0.69(0.34,1.43) \quad 2.45$

$0.67(0.57,0.78) \quad 100.00$

A2

Study

ID

Progression-free survival(BRCA1/2 mutation)

Sabatier (2016)

Harter (2015)

Zhang (2014)

Rudaitis (2014)

Dann (2012)

Alsop (2012)

Yang (2011)

Lacour (2011)

Hennessy (2010)

Tan (2008)

Majdak (2005)

Cass (2003)

Aida (1998)

Subtotal (I-squared $=18.1 \%, p=0.261)$

NOTE: Weights are from random effects analysis
$\%$

HR $(95 \% \mathrm{Cl}) \quad$ Weight

$1.37(0.83,2.27) \quad 7.86$

$0.55(0.39,0.77) \quad 14.23$

$0.52(0.21,1.30) \quad 2.73$

$0.62(0.38,1.00) \quad 8.42$

$0.62(0.29,1.32) \quad 3.84$

$0.65(0.48,0.88) \quad 16.55$

$0.60(0.40,0.88) \quad 11.53$

$0.59(0.42,0.82) \quad 14.55$

$0.61(0.39,0.94) \quad 9.75$

$0.22(0.08,0.65) \quad 2.10$

$0.58(0.31,1.09) \quad 5.37$

$0.45(0.18,1.17) \quad 2.60$

$0.75(0.08,6.90) \quad 0.48$

$0.62(0.53,0.73) \quad 100.00$ 

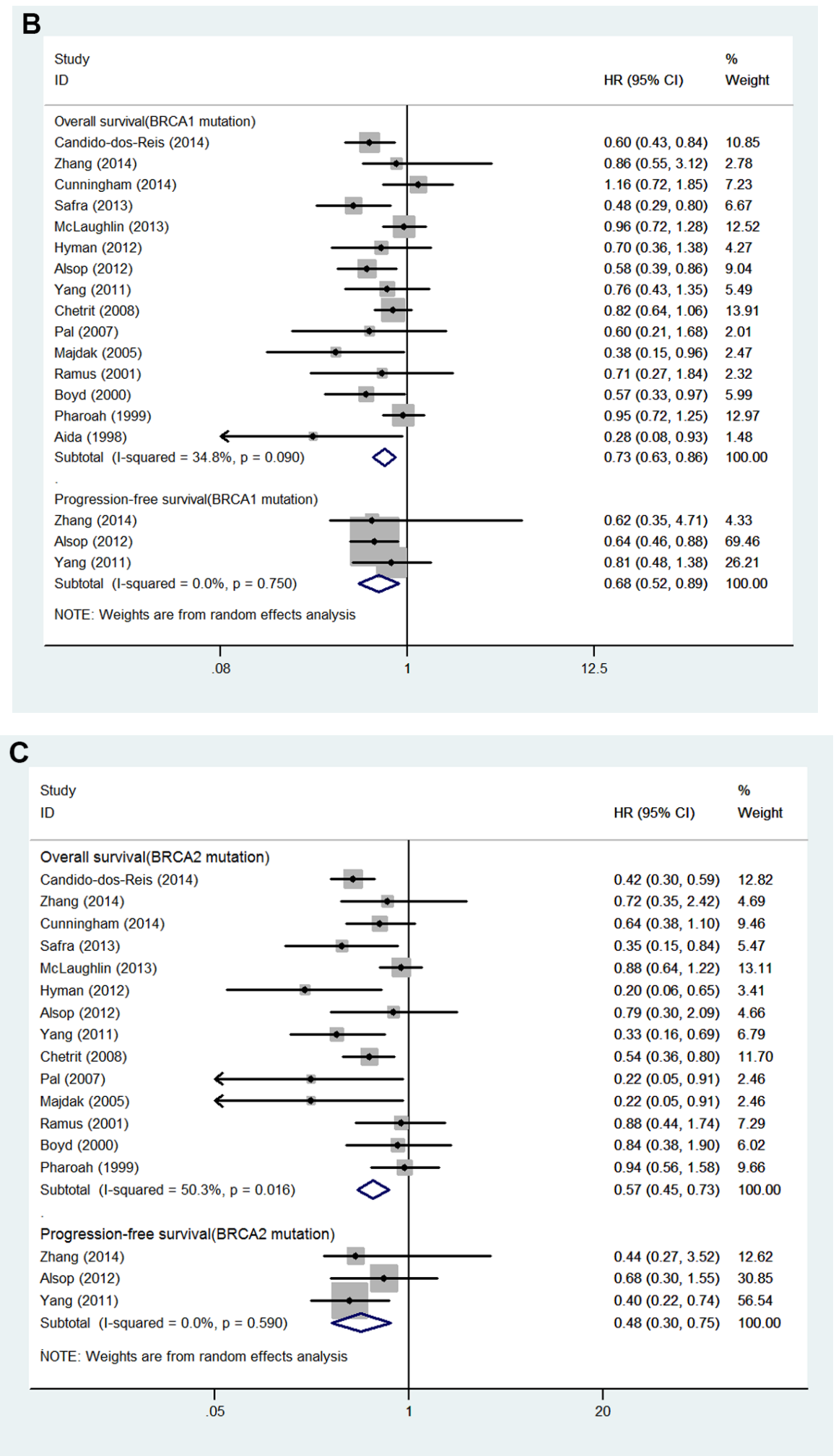

Figure 2: (A) Forest plot for the association between BRCA1/2 mutation and ovarian cancer (1) overall survival and (2) progression-free survival. (B) Forest plot for the association between BRCA1 mutation and ovarian cancer overall survival and progression-free survival; (C) Forest plot for the association between $B R C A 2$ mutation and ovarian cancer overall survival and progressionfree survival. 

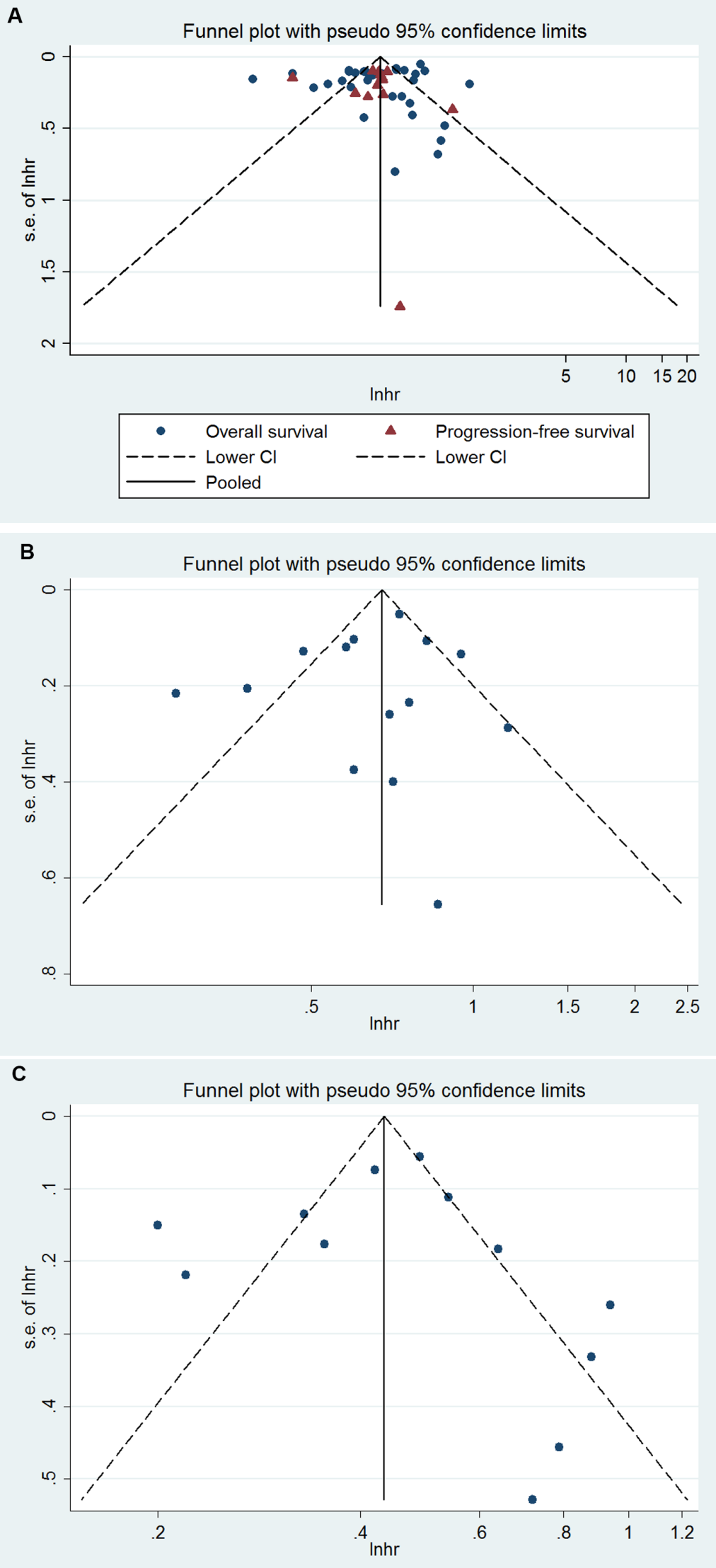

Figure 3: Funnel plot for (A) BRCA1/2, (B) BRCA1, (C) BRCA2 mutation and ovarian cancer overall survival and/or progression-free survival. 
Table 3A: Subgroup analyses stratified by some of the baseline characteristics for associations between $B R C A 1 / 2$ mutation and progression-free survival

\begin{tabular}{|c|c|c|c|c|c|}
\hline & HR & $95 \% \mathrm{CI}$ & $\begin{array}{l}\text { Degree of heterogeneity } \\
\text { (I }{ }^{2} \text { statistics; \%) }\end{array}$ & $P$ & $\begin{array}{l}\text { No. of included } \\
\text { Studies }\end{array}$ \\
\hline Total & 0.62 & 0.53 to 0.73 & 18.1 & 0.261 & 13 \\
\hline \multicolumn{6}{|l|}{ Study quality } \\
\hline Score $>7$ & 0.65 & 0.52 to 0.81 & 40.9 & 0.118 & 7 \\
\hline$\leq 7$ & 0.59 & 0.46 to 0.75 & 0 & 0.523 & 6 \\
\hline \multicolumn{6}{|l|}{ Stage of disease } \\
\hline I-IV & 0.74 & 0.47 to 1.15 & 63.0 & 0.044 & 4 \\
\hline II-IV & 0.55 & 0.43 to 0.69 & 0 & 0.520 & 5 \\
\hline III-IV & 0.60 & 0.48 to 0.76 & 0 & 0.996 & 4 \\
\hline \multicolumn{6}{|l|}{ Study design } \\
\hline Cohort & 0.64 & 0.55 to 0.74 & 15.9 & 0.296 & 10 \\
\hline Case-control & 0.44 & 0.22 to 0.86 & 4 & 0.271 & 3 \\
\hline \multicolumn{6}{|l|}{ Sample size } \\
\hline$\geq 200$ & 0.61 & 0.51 to 0.72 & 0 & 0.996 & 6 \\
\hline$<200$ & 0.62 & 0.37 to 1.04 & 60.7 & 0.026 & 6 \\
\hline \multicolumn{6}{|l|}{ Research center } \\
\hline Single & 0.65 & 0.54 to 0.78 & 24 & 0.230 & 9 \\
\hline Multicenter & 0.56 & 0.42 to 0.75 & 10.7 & 0.340 & 4 \\
\hline \multicolumn{6}{|c|}{$\begin{array}{l}\text { Duration of follow-up } \\
\text { Months }\end{array}$} \\
\hline$>60$ & 0.60 & 0.30 to 1.18 & 74.6 & 0.005 & 4 \\
\hline$\leq 60$ & 0.60 & 0.51 to 0.70 & 42.2 & 0.995 & 7 \\
\hline \multicolumn{6}{|c|}{$\begin{array}{l}\text { Adequate baseline } \\
\text { characteristics adjusted }\end{array}$} \\
\hline Yes & 0.62 & 0.53 to 0.73 & 18.1 & 0.261 & 13 \\
\hline No & l & l & l & l & 0 \\
\hline \multicolumn{6}{|l|}{ Histology } \\
\hline All & 0.64 & 0.52 to 0.78 & 28.4 & 0.175 & 11 \\
\hline High-grade serous & 0.60 & 0.40 to 0.89 & l & 1 & 1 \\
\hline \multicolumn{6}{|l|}{ Mutation ratio } \\
\hline$>25 \%$ & 0.60 & 0.51 to 0.71 & 0 & 0.987 & 6 \\
\hline$\leq 25 \%$ & 0.63 & 0.43 to 0.92 & 55.6 & 0.036 & 7 \\
\hline \multicolumn{6}{|l|}{ Region } \\
\hline Europe & 0.63 & 0.40 to 0.98 & 70.7 & 0.008 & 5 \\
\hline America/Canada & 0.59 & 0.48 to 0.73 & 0 & 0.985 & 5 \\
\hline Asia & 0.75 & 0.08 to 6.90 & 1 & l & 1 \\
\hline \multicolumn{6}{|c|}{ Optimal debulking ratio } \\
\hline$>65 \%$ & 0.70 & 0.50 to 1.00 & 55.1 & 0.063 & 5 \\
\hline$\leq 65 \%$ & 0.63 & 0.50 to 0.79 & 0 & 0.938 & 3 \\
\hline
\end{tabular}

Abbreviations: $\mathrm{HR}=$ hazard ratio; $\mathrm{CI}=$ confidence interval.

in genomic instability and having a tendency to malignant transformation [3]. On the other hand, the impairment of this pathway can also influence DNA cross-links by tumor cells, which can be induced by cisplatin, a chemotherapy agent for ovarian cancer. It has been indicated that $B R C A$ deficient patients can have better survival outcomes through the increase in the response rate to platinum-based chemotherapy $[7,8]$.
The findings of this updated meta-analysis are generally consistent with and further extend the other two published systematic reviews and meta-analyses in several important ways. First, our study had added greater statistical power to the associations between $B R C A$ mutations and ovarian cancer survival with more detailed subgroup analyses. For example, the present meta-analysis involved approximately 2.3 times as 
Table 3B: Subgroup analyses stratified by some of the baseline characteristics for associations between $B R C A 1$ mutation and progression-free survival

\begin{tabular}{|c|c|c|c|c|c|}
\hline & HR & $95 \% \mathrm{CI}$ & $\begin{array}{c}\text { Degree of heterogeneity } \\
\left(I^{2} \text { statistics; \%) }\right.\end{array}$ & $P$ & $\begin{array}{l}\text { No. of included } \\
\text { Studies }\end{array}$ \\
\hline \multicolumn{6}{|l|}{ Total } \\
\hline & 0.68 & 0.52 to 0.89 & 0 & 0.750 & 3 \\
\hline \multicolumn{6}{|l|}{ Study quality } \\
\hline Score $>7$ & 0.78 & 0.48 to 1.27 & 0 & 0.709 & 2 \\
\hline$\leq 7$ & 0.64 & 0.46 to 0.88 & l & l & 1 \\
\hline \multicolumn{6}{|l|}{ Stage of disease } \\
\hline I-IV & 0.64 & 0.46 to 0.88 & 1 & I & 1 \\
\hline II-IV & 0.78 & 0.48 to 1.27 & 0 & 0.709 & 2 \\
\hline III-IV & / & I & l & l & 0 \\
\hline \multicolumn{6}{|l|}{ Study design } \\
\hline Cohort & 0.68 & 0.52 to 0.89 & 0 & 0.750 & 3 \\
\hline Case-control & / & l & l & l & 0 \\
\hline \multicolumn{6}{|l|}{ Sample size } \\
\hline$\geq 200$ & 0.68 & 0.52 to 0.89 & 0 & 0.750 & 3 \\
\hline$<200$ & l & l & l & l & 0 \\
\hline \multicolumn{6}{|l|}{ Research center } \\
\hline Single & 0.68 & 0.52 to 0.89 & 0 & 0.750 & 3 \\
\hline Multicenter & / & / & l & l & 0 \\
\hline \multicolumn{6}{|c|}{ Duration of follow-up } \\
\hline$>60$ & 0.64 & 0.46 to 0.88 & / & / & 1 \\
\hline$\leq 60$ & 0.78 & 0.48 to 1.27 & 0 & 0.709 & 2 \\
\hline \multicolumn{6}{|c|}{$\begin{array}{l}\text { Adequate baseline } \\
\text { characteristics adjusted }\end{array}$} \\
\hline Yes & 0.68 & 0.52 to 0.89 & 0 & 0.750 & 3 \\
\hline No & l & l & l & l & 0 \\
\hline \multicolumn{6}{|l|}{ Histology } \\
\hline All & 0.70 & 0.59 to 0.83 & 35.5 & 0.099 & 2 \\
\hline High-grade serous & 0.81 & 0.48 to 1.37 & l & l & 1 \\
\hline \multicolumn{6}{|l|}{ Region } \\
\hline Europe & 1 & I & l & I & 0 \\
\hline America/Canada & 0.81 & 0.48 to 1.38 & 1 & I & 1 \\
\hline Asia & I & 1 & 1 & I & 0 \\
\hline
\end{tabular}

Abbreviations: $\mathrm{HR}=$ hazard ratio; $\mathrm{CI}=$ confidence interval.

many participants as the previous two studies [24, 25]. As a matter of fact, 11 recent published cohort studies were involved in the analyses. Second, three mutation subtypes (BRCA1/2, BRCA1 and BRCA2) were thoroughly investigated in contrast to the earlier two meta-analyses (including only BRCA1 and BRCA2 subtypes). Thirdly, we did detailed subgroup analyses under a broader range of study level circumstances to examine the potential sources of heterogeneity. However, our findings concur with the previous meta-analyses. Inter-study heterogeneity was found very high for a number of analyses, which was probably due to the very variation in population characteristics and $B R C A$ mutation detection methods.
Thus, caution is required when interpreting these findings. Moreover, one important advantage of this meta-analyses lies in that we have thoroughly tested the influence of publication bias through Begg's test, Egger's test and sensitivity analysis and confirmed the robustness of the findings.

Several limitations of this meta-analysis are required to be addressed. We acknowledge that the results of this meta-analysis were derived from published data rather than from studies of individual patient data. Thus, we could not obtained the detailed characteristics of each individual from the involved studies including patient age, tumor stage, sample size, and follow-up period, which to 
Table 3C: Subgroup analyses stratified by some of the baseline characteristics for associations between $B R C A 2$ mutation and progression-free survival

\begin{tabular}{|c|c|c|c|c|c|}
\hline & HR & $95 \% \mathrm{CI}$ & $\begin{array}{c}\text { Degree of heterogeneity } \\
\left(I^{2} \text { statistics; \% }\right)\end{array}$ & $P$ & $\begin{array}{c}\begin{array}{c}\text { No. of included } \\
\text { Studies }\end{array} \\
\end{array}$ \\
\hline \multicolumn{6}{|l|}{ Total } \\
\hline & 0.48 & 0.30 to 0.75 & 0 & 0.590 & 3 \\
\hline \multicolumn{6}{|l|}{ Study quality } \\
\hline Score $>7$ & 0.41 & 0.24 to 0.70 & 0 & 0.895 & 2 \\
\hline$\leq 7$ & 0.68 & 0.30 to 1.55 & l & I & 1 \\
\hline \multicolumn{6}{|l|}{ Stage of disease } \\
\hline I-IV & 0.68 & 0.30 to 1.55 & 1 & 1 & 1 \\
\hline II-IV & 0.41 & 0.24 to 0.70 & 0 & 0.895 & 2 \\
\hline III-IV & l & / & l & l & 0 \\
\hline \multicolumn{6}{|l|}{ Study design } \\
\hline Cohort & 0.48 & 0.30 to 0.75 & 0 & 0.590 & 3 \\
\hline Case-control & l & / & l & l & 0 \\
\hline \multicolumn{6}{|l|}{ Sample size } \\
\hline$\geq 200$ & 0.48 & 0.30 to 0.75 & 0 & 0.590 & 3 \\
\hline$<200$ & l & l & l & 1 & 0 \\
\hline \multicolumn{6}{|l|}{ Research center } \\
\hline Single & 0.48 & 0.30 to 0.75 & 0 & 0.590 & 3 \\
\hline Multicenter & 1 & 1 & 1 & 1 & 0 \\
\hline \multicolumn{6}{|c|}{ Duration of follow-up } \\
\hline$>60$ & 0.68 & 0.30 to 1.55 & l & / & 1 \\
\hline$\leq 60$ & 0.41 & 0.24 to 0.70 & 0 & 0.895 & 2 \\
\hline \multicolumn{6}{|c|}{$\begin{array}{l}\text { Adequate baseline } \\
\text { characteristics adjusted }\end{array}$} \\
\hline Yes & 0.48 & 0.30 to 0.75 & 0 & 0.590 & 3 \\
\hline No & l & l & l & l & 0 \\
\hline \multicolumn{6}{|l|}{ Histology } \\
\hline All & 0.40 & 0.22 to 0.73 & I & l & 1 \\
\hline High-grade serous & 0.60 & 0.30 to 1.20 & 0 & 0.576 & 2 \\
\hline \multicolumn{6}{|l|}{ Region } \\
\hline Europe & I & l & 1 & I & 0 \\
\hline America/Canada & 0.40 & 0.22 to 0.74 & I & l & 1 \\
\hline Asia & 1 & I & 1 & 1 & 0 \\
\hline
\end{tabular}

Abbreviations: $\mathrm{HR}=$ hazard ratio; $\mathrm{CI}=$ confidence interval.

some extent were contributory factors to the heterogeneity, but an attempt was made to account for this variation by conducting subgroup analyses. Another potential limitation of the study is that we also include some conference abstracts in the analysis. It is likely that the results may differ to certain extent between the conference abstracts and future updated full publication. However, we proposed that such differences are very likely to be relatively mild. Moreover, the method for the detection of $B R C A$ mutation varied among studies, which may also a source of substantial heterogeneity. Some of the included studies did not report complete data for analysis, and could have potentially affected the results of multivariate analysis. Most of the included studies adequately adjusted for some known confounders, in particular patients age, tumor stage and grade or chemotherapy. However, some studies did not assess these factors and we acknowledge this limitation. As these were all studies with small sample size, it is unlikely to have affected the results of the analysis substantially. Although no obvious evidence of publication bias was noted in each subset of metaanalysis, it was still a major concern. Due to the time taken to conduct this meta-analysis, further relevant studies concerning this topic may have been published. However, given the relative paucity of suitable studies identified through the last 20 years from 1996 to 2016, we proposed 
that there were probably very few studies in number and they would not substantially affect the general conclusions of this study.

Despite all of these limitations, however, our meta-analysis with a large sample size of over 18,396 participants, and used the appropriate analyses to investigate the heterogeneity and publication bias among the different studies, showed that in patients with ovarian cancer, $B R C A$ mutation (irrespective of its subtypes) carriers had better OS and PFS than non-carriers. Whether the results may have therapeutic implications remains to be elucidated with further larger, well-designed studies in specific ovarian cancer patients.

\section{MATERIALS AND METHODS}

\section{Literature search and study selection}

PubMed and EMBASE were searched for studies published up to February 2016 for the following searching terms: (ovary/ovarian/oophor* and cancer/neoplas*/ tumor*/tumour*/_ cancer*/carcinoma*/malignan*/ neoplasms) and (BRCA1/2 and mutation*/mutated) and mortality/survival/prognosis. Mesh (Pubmed) and Emtree (Embase) terms combined with free text words were used for searching. Detailed search terms and strategies for the two databases are presented in Supplementary Appendix 1. In addition, we also conducted the manual searches of references in all eligible studies to identify potential missing publications that were not identified during the preliminary literature searches. We did not place any restrictions on the searches.

Studies were considered eligible if they met the following inclusion criteria: observational studies (cohort or case-control studies) that investigated patients with ovarian cancer assessed for $B R C A$ mutation status (BRCA1 or BRCA2 mutation status). The outcome measures included OS and PFS, measured as the relative risk (RR), the odds ratio (OR), or the hazard ratio (HR) along with the $95 \%$ confidence interval (CI) (or sufficient data for calculating them). We did not include studies with unpublished data. If multiple reports contained the duplicated datasets, the report with the largest or the most recent data was included for analysis. Two investigators independently conducted the literature review (KX and $\mathrm{SHY}$ ) and any discrepancies were resolved by discussion or by a senior investigator (YCZ).

\section{Data extraction and quality assessment}

Two investigators independently extracted data from each included study using a predefined standardized data extraction form including the pertinent issues that concerned the characteristics and survival outcomes of the ovarian cancer patients. For each article, the following information was extracted: authors and published years, study design, sample size, inclusion period, research country, disease stage, tumor histology, BRCA mutation detection methods, research center involved, duration of follow-up and adjusted variables. The extracted data were crosschecked and any disagreements were resolved by discussion.

\section{Outcome measures}

The primary outcome measure was OS defined as the time from initial ovarian cancer diagnosis to death due to any causes. Secondary outcome was PFS defined as the time from diagnosis to the first confirmed sign of cancer recurrence, or progression (disease relapse or metastasis) or death from any cause.

\section{Quality assessment}

The nine-star Newcastle-ottawa Scale (NOS) [44] was used to assess the study quality for each study. Three domains associated with the selection of study population, data comparability and exposure (case-control studies) or outcome (cohort studies) assessment were evaluated. The NOS score ranged from 0 to 9 with a score $>7$ indicating high quality. Two investigators scored each study, and any discrepancies were resolved by a third investigator.

\section{Statistical analysis}

All statistical analyses were performed using Stata statistical software (version 12.0; Stata Corporation, College Station, TX, USA). Pooled HRs for OS and PFS with 95\% CIs were calculated using random-effects model due to the potential substantial heterogeneity between studies [45]. Heterogeneity across studies was examined by $\mathrm{I}^{2}$ statistic with an $\mathrm{I}^{2} \geq 50 \%$ indicating the presence of significant heterogeneity [46]. We further investigated potential heterogeneity by subgroup analyses stratified by study quality, tumor stage, study design, sample size, number of research center, duration of follow-up, baseline characteristics adjusted, mutation ratio and tumor histology for OS and PFS across BRCA1/2, BRCA1 and $B R C A 2$ mutation subgroups. Publication bias was evaluated by observing the asymmetry of funnel plots and using the Begg-Mazumdar rank correlation test and Egger's test [47, 48]. The Duval and Tweedie trimand-fill method was also applied to conduct sensitivity analysis [49]. A two-sided $P \leq 0.05$ was considered statistically significant.

\section{Abbreviations}

CI: 95\% confidence interval; HR: hazard ratios; NOS: Newcastle-ottawa Scale; OS: overall survival; PRISMA: the Preferred Reporting Items for Systematic 
Reviews and Meta-Analyses; PFS: progression-free survival.

\section{ACKNOWLEDGMENTS}

This research was supported by National Natural Science Foundation of China (Grant No. 81502657)

\section{CONFLICTS OF INTEREST}

The authors indicated no financial relationships.

\section{Authors'contributions}

Conception/Design: Yingchao Zhao. Provision of study materials or patients: Kai Xu, Shouhua Yang, Yingchao Zhao. Collection and/or extract data: Kai $\mathrm{Xu}$, Shouhua Yang, Yingchao Zhao. Data analysis and statistical guidance: Kai Xu, Shouhua Yang, Yingchao Zhao. Manuscript writing: Kai Xu, Shouhua Yang, Yingchao Zhao. Final approval of the manuscript: Kai Xu, Shouhua Yang, Yingchao Zhao.

\section{REFERENCES}

1. Friebel TM, Domchek SM, Rebbeck TR. Modifiers of cancer risk in BRCA1 and BRCA2 mutation carriers: systematic review and meta-analysis. J Natl Cancer Inst. 2014; 106:dju091.

2. Mavaddat N, Peock S, Frost D, Ellis S, Platte R, Fineberg E, Evans DG, Izatt L, Eeles RA, Adlard J, Davidson R, Eccles D, Cole T, et al. Cancer risks for BRCA1 and BRCA2 mutation carriers: results from prospective analysis of EMBRACE. J Natl Cancer Inst. 2013; 105:812-22.

3. Girolimetti G, Perrone AM, Santini D, Barbieri E, Guerra F, Ferrari S, Zamagni C, De Iaco P, Gasparre G, Turchetti D. BRCA-associated ovarian cancer: from molecular genetics to risk management. Biomed Res Int. 2014; 2014:787143.

4. Beck C, Robert I, Reina-San-Martin B, Schreiber V, Dantzer F. Poly(ADP-ribose) polymerases in double-strand break repair: focus on PARP1, PARP2 and PARP3. Exp Cell Res. 2014; 329:18-25.

5. Roy R, Chun J, Powell SN. BRCA1 and BRCA2: different roles in a common pathway of genome protection. Nat Rev Cancer. 2012; 12:68-78.

6. Aparicio T, Baer R, Gautier J. DNA double-strand break repair pathway choice and cancer. DNA Repair (Amst). 2014; 19:169-75.

7. Dann RB, DeLoia JA, Timms KM, Zorn KK, Potter J, Flake DD, 2nd, Lanchbury JS, Krivak TC. BRCA1/2 mutations and expression: response to platinum chemotherapy in patients with advanced stage epithelial ovarian cancer. Gynecol Oncol. 2012; 125:677-82.

8. Tan DS, Rothermundt C, Thomas K, Bancroft E, Eeles R, Shanley S, Ardern-Jones A, Norman A, Kaye SB, Gore ME.
"BRCAness" syndrome in ovarian cancer: a case-control study describing the clinical features and outcome of patients with epithelial ovarian cancer associated with BRCA1 and BRCA2 mutations. J Clin Oncol. 2008; 26:5530-6.

9. Synowiec A, Wcislo G, Bodnar L, Gorski B, Szenajch J, Szarlej-Wcislo K, Szczylik C. Clinical features and outcomes of germline mutation BRCA1-linked versus sporadic ovarian cancer patients. Hered Cancer Clin Pract. 2016; $14: 1$.

10. Harter $\mathrm{P}$, Johnson $\mathrm{T}$, Berton-Rigaud D, Park SY, Friedlander M, Del Campo JM, Shimada M, Forget F, Mirza MR, Colombo N, Zamagni C, Chan JK, Imhof M, et al. BRCA1/2 mutations associated with progression-free survival in ovarian cancer patients in the AGO-OVAR 16 study. Gynecol Oncol. 2015.

11. Chen P, Huhtinen K, Kaipio K, Mikkonen P, Aittomaki V, Lindell R, Hynninen J, Auranen A, Grenman S, Lehtonen R, Carpen O, Hautaniemi S. Identification of Prognostic Groups in High-Grade Serous Ovarian Cancer Treated with Platinum-Taxane Chemotherapy. Cancer Res. 2015; 75:2987-98.

12. Candido-dos-Reis FJ, Song H, Goode EL, Cunningham JM, Fridley BL, Larson MC, Alsop K, Dicks E, Harrington P, Ramus SJ, de Fazio A, Mitchell G, Fereday S, et al. Germline mutation in BRCA1 or BRCA2 and ten-year survival for women diagnosed with epithelial ovarian cancer. Clin Cancer Res. 2015; 21:652-7.

13. Zhang S, Yuan Y, Hao D. A genomic instability score in discriminating nonequivalent outcomes of BRCA1/2 mutations and in predicting outcomes of ovarian cancer treated with platinum-based chemotherapy. PLoS One. 2014; 9:e113169.

14. Pennington KP, Walsh T, Harrell MI, Lee MK, Pennil CC, Rendi MH, Thornton A, Norquist BM, Casadei S, Nord AS, Agnew KJ, Pritchard CC, Scroggins S, et al. Germline and somatic mutations in homologous recombination genes predict platinum response and survival in ovarian, fallopian tube, and peritoneal carcinomas. Clin Cancer Res. 2014; 20:764-75.

15. Chan J, Kiet T, Chen L, Ruskin R, Sherman A, Lesnock J, Monk B, Kapp D, Krivak T. Chemotherapy response and survival in serous ovarian cancer patients with BRCA mutations. Gynecologic Oncology. 2012; 125:S85.

16. Gallagher DJ, Konner JA, Bell-McGuinn KM, Bhatia J, Sabbatini P, Aghajanian CA, Offit K, Barakat RR, Spriggs DR, Kauff ND. Survival in epithelial ovarian cancer: a multivariate analysis incorporating BRCA mutation status and platinum sensitivity. Ann Oncol. 2011; 22:1127-32.

17. David YB, Chetrit A, Hirsh-Yechezkel G, Friedman E, Beck BD, Beller U, Ben-Baruch G, Fishman A, Levavi H, Lubin F, Menczer J, Piura B, Struewing JP, et al. Effect of BRCA mutations on the length of survival in epithelial ovarian tumors. Journal of Clinical Oncology. 2002; 20:463-6. 
18. Rubin SC, Benjamin I, Behbakht $\mathrm{K}$, Takahashi H, Morgan MA, LiVolsi VA, Berchuck A, Muto MG, Garber JE, Weber BL, Lynch HT, Boyd J. Clinical and pathological features of ovarian cancer in women with germ-line mutations of BRCA1. N Engl J Med. 1996; 335:1413-6.

19. Kotsopoulos J, Rosen B, Fan I, Moody J, McLaughlin JR, Risch H, May T, Sun P, Narod SA. Ten-year survival after epithelial ovarian cancer is not associated with BRCA mutation status. Gynecol Oncol. 2016; 140:42-7.

20. Sabatier R, Lavit E, Moretta J, Lambaudie E, Noguchi T, Eisinger F, Cherau E, Provansal M, Livon D, Rabayrol L, Popovici C, Charaffe-Jauffret E, Sobol H, et al. Ovarian cancer patients at high risk of BRCA mutation: the constitutional genetic characterization does not change prognosis. Fam Cancer. 2016.

21. Buller RE, Shahin MS, Geisler JP, Zogg M, De Young BR, Davis CS. Failure of BRCA1 dysfunction to alter ovarian cancer survival. Clin Cancer Res. 2002; 8:1196-202.

22. Jóhannsson Ó T, Ranstam J, Borg Å, Olsson H. Survival of BRCA1 breast and ovarian cancer patients: A populationbased study from Southern Sweden. Journal of Clinical Oncology. 1998; 16:397-404.

23. Zweemer RP, Verheijen RH, Coebergh JW, Jacobs IJ, van Diest PJ, Gille JJ, Skates S, Menko FH, Ten Kate LP, Kenemans P. Survival analysis in familial ovarian cancer, a case control study. European journal of obstetrics, gynecology, and reproductive biology. 2001; 98:219-23.

24. Sun C, Li N, Ding D, Weng D, Meng L, Chen G, Ma D. The role of BRCA status on the prognosis of patients with epithelial ovarian cancer: a systematic review of the literature with a meta-analysis. PLoS One. 2014; 9:e95285.

25. Zhong Q, Peng HL, Zhao X, Zhang L, Hwang WT. Effects of BRCA1- and BRCA2-related mutations on ovarian and breast cancer survival: a meta-analysis. Clin Cancer Res. 2015; 21:211-20.

26. Rudaitis V, Zvirblis T, Kanopiene D, Janulynaite D, Griskevicius L, Janavicius R. BRCA1/2 mutation status is an independent factor of improved survival for advanced (stage III-IV) ovarian cancer. Int J Gynecol Cancer. 2014; 24:1395-400.

27. Alsop K, Fereday S, Meldrum C, deFazio A, Emmanuel C, George J, Dobrovic A, Birrer MJ, Webb PM, Stewart C, Friedlander M, Fox S, Bowtell D, et al. BRCA mutation frequency and patterns of treatment response in BRCA mutation-positive women with ovarian cancer: a report from the Australian Ovarian Cancer Study Group. J Clin Oncol. 2012; 30:2654-63.

28. Yang D, Khan S, Sun Y, Hess K, Shmulevich I, Sood AK, Zhang W. Association of BRCA1 and BRCA2 mutations with survival, chemotherapy sensitivity, and gene mutator phenotype in patients with ovarian cancer. Jama. 2011; 306:1557-65.
29. Lacour RA, Westin SN, Meyer LA, Wingo SN, Schorge JO, Brooks R, Mutch D, Molina A, Sutphen R, Barnes M, Elder J, Teoh D, Powell CB, et al. Improved survival in nonAshkenazi Jewish ovarian cancer patients with BRCA1 and BRCA2 gene mutations. Gynecol Oncol. 2011; 121:358-63.

30. Hennessy BTJ, Timms KM, Carey MS, Gutin A, Meyer LA, Flake DD, Abkevich V, Potter J, Pruss D, Glenn P, Li Y, Li J, Gonzalez-Angulo AM, et al. Somatic mutations in BRCA1 and BRCA2 could expand the number of patients that benefit from poly (ADP ribose) polymerase inhibitors in ovarian cancer. Journal of Clinical Oncology. 2010; 28:3570-6.

31. Tan DSP, Rothermundt C, Thomas K, Bancroft E, Eeles R, Shanley S, Ardern-Jones A, Norman A, Kaye SB, Gore ME. "BRCAness" syndrome in ovarian cancer: A case-control study describing the clinical features and outcome of patients with epithelial ovarian cancer associated with BRCA1 and BRCA2 mutations. Journal of Clinical Oncology. 2008; 26:5530-6.

32. Majdak EJ, De Bock GH, Brozek I, Perkowska M, Ochman K, Debniak J, Milczek T, Cornelisse CJ, Jassem J, Emerich J, Limon J, Devilee P. Prevalence and clinical correlations of BRCA1/BRCA2 unclassified variant carriers among unselected primary ovarian cancer cases preliminary report. Eur J Cancer. 2005; 41:143-50.

33. Cass I, Baldwin RL, Varkey T, Moslehi R, Narod SA, Karlan BY. Improved survival in women with BRCAassociated ovarian carcinoma. Cancer. 2003; 97:2187-195.

34. Aida H, Takakuwa K, Nagata H, Tsuneki I, Takano M, Tsuji S, Takahashi T, Sonoda T, Hatae M, Takahashi K, Hasegawa K, Mizunuma $\mathrm{H}$, Toyoda N, et al. Clinical features of ovarian cancer in Japanese women with germ-line mutations of BRCA1. Clin Cancer Res. 1998; 4:235-40.

35. Cunningham JM, Cicek MS, Larson NB, Davila J, Wang C, Larson MC, Song H, Dicks EM, Harrington P, Wick M, Winterhoff BJ, Hamidi H, Konecny GE, et al. Clinical characteristics of ovarian cancer classified by BRCA1, BRCA2, and RAD51C status. Scientific reports. 2014; 4:4026.

36. Safra T, Lai WC, Borgato L, Nicoletto MO, Berman T, Reich E, Alvear M, Haviv I, Muggia FM. BRCA mutations and outcome in epithelial ovarian cancer (EOC): experience in ethnically diverse groups. Ann Oncol. 2013; 24: viii63-viii8.

37. McLaughlin JR, Rosen B, Moody J, Pal T, Fan I, Shaw PA, Risch HA, Sellers TA, Sun P, Narod SA. Long-term ovarian cancer survival associated with mutation in BRCA1 or BRCA2. J Natl Cancer Inst. 2013; 105:141-48.

38. Hyman DM, Zhou Q, Iasonos A, Grisham RN, Arnold AG, Phillips MF, Bhatia J, Levine DA, Aghajanian C, Offit K, Barakat RR, Spriggs DR, Kauff ND. Improved survival for BRCA2-associated serous ovarian cancer compared with both BRCA-negative and BRCA1-associated serous ovarian cancer. Cancer. 2012; 118:3703-709. 
39. Chetrit A, Hirsh-Yechezkel G, Ben-David Y, Lubin F, Friedman E, Sadetzki S. Effect of BRCA1/2 mutations on long-term survival of patients with invasive ovarian cancer: the national Israeli study of ovarian cancer. J Clin Oncol. 2008; 26:20-5.

40. Pal T, Permuth-Wey J, Kapoor R, Cantor A, Sutphen R. Improved survival in BRCA2 carriers with ovarian cancer. Fam Cancer. 2007; 6:113-19.

41. Ramus SJ, Fishman A, Pharoah PD, Yarkoni S, Altaras M, Ponder BA. Ovarian cancer survival in Ashkenazi Jewish patients with BRCA1 and BRCA2 mutations. Eur J Surg Oncol. 2001; 27:278-81.

42. Boyd J, Sonoda Y, Federici MG, Bogomolniy F, Rhei E, Maresco DL, Saigo PE, Almadrones LA, Barakat RR, Brown CL, Chi DS, Curtin JP, Poynor EA, et al. Clinicopathologic features of BRCA-linked and sporadic ovarian cancer. Jama. 2000; 283:2260-265.

43. Pharoah PD, Easton DF, Stockton DL, Gayther S, Ponder BA. Survival in familial, BRCA1-associated, and BRCA2-associated epithelial ovarian cancer. United Kingdom Coordinating Committee for Cancer Research (UKCCCR) Familial Ovarian Cancer Study Group. Cancer Res. 1999; 59:868-71.
44. Wells GA, Shea B, O'Connell D, Peterson J, Welch V, Losos M, Tugwell P. The Newcastle-Ottawa Scale (NOS) for assessing the quality of nonrandomized studies in metaanalyses. 2000.

45. Begg CB, Mazumdar M. Operating characteristics of a rank correlation test for publication bias. Biometrics. 1994; 50:1088-101.

46. DerSimonian R, Laird N. Meta-analysis in clinical trials. Control Clin Trials. 1986; 7:177-88.

47. Duval S, Tweedie R. Trim and fill: A simple funnel-plotbased method of testing and adjusting for publication bias in meta-analysis. Biometrics. 2000; 56:455-63.

48. Egger M, Davey Smith G, Schneider M, Minder C. Bias in meta-analysis detected by a simple, graphical test. BMJ. 1997; 315:629-34.

49. Higgins JP, Thompson SG, Deeks JJ, Altman DG. Measuring inconsistency in meta-analyses. BMJ. 2003; 327:557-60. 